\section{Quick Facts}

Natcore Technology Inc., based in Red Bank, New Jersey, has licensed the NREL black silicon technology and is incorporating it into its proprietary manufacturing process for solar cells.

Natcore, a startup company, is investing roughly $\$ 2$ million in a research facility in Rochester, New York.

Increases in manufactured cell efficiencies of up to $0.8 \%$ are possible because of the reduced reflectance of black silicon. This would reduce silicon solar module costs by \$5-\$10 per module.

Compared to conventional silicon solar cells, those treated with NREL's black silicon etch are able to absorb more sunlight when the sun is hitting the solar cell at a sharp angle. The superior angle-ofincidence performance of black silicon may result in solar modules that produce $1 \%$ $3 \%$ more energy, because of better performance in the morning and evening and under diffuse light conditions.

Increasing the efficiency and energy production of solar modules will reduce some balance-of-system costs. Fewer modules mean fewer racks and lower installation costs.

Because of the great potential for NREL's black silicon etch to cut manufacturing costs, R\&D Magazine honored the technology with an R\&D 100 Award in 2010 , identifying it as one of the top 100 technological innovations of the year.

National Renewable Energy Laboratory 15013 Denver West Parkway, Golden, CO 80401 303-275-3000 • www.nrel.gov

NREL is a national laboratory of the U.S. Department of Energy, Office of Energy Efficiency and Renewable Energy, operated by the Alliance for Sustainable Energy, LLC.

NREL/FS-6A42-59020 • August 2013

Printed with a renewable-source ink on paper containing at least $50 \%$ wastepaper, including $10 \%$ post consumer waste.

\section{Award-Winning Etching Process Cuts Solar Cell Costs}

Optimizing solar-cell technology can be a complex job, requiring expertise in material science, physics, and optics to convert as much sunlight as possible into electricity. But despite this complexity, a simple fact is key to making a highperformance solar cell: any sunlight reflected off the cell can't possibly be converted into electricity.

Manufacturers have tried to minimize the reflection of sunlight off of solar cells by first chemically etching micrometers-deep structures into the surface of solar cells and then depositing one or more thin anti-reflection layers. Unfortunately, the equipment and processes for these conventional methods add significant cost to the solar cell, and the cells still absorb only $93 \%-97 \%$ of the sunlight.

To address this problem, scientists at the National Renewable Energy Laboratory (NREL) have invented the "black silicon" nanocatalytic wet-chemical etch, an inexpensive, one-step process that literally turns the solar cells black, allowing them to absorb more than $98 \%$ of incident sunlight. The process costs just a few cents per watt of solar-cell power-producing capacity.

To etch the silicon, a wafer is immersed in a solution that contains chloroauric acid, which is composed of hydrogen, chlorine, and gold. Tiny nanoparticles of gold instantly form and act as a catalyst for chemical reactions, producing a nanometerscale porous surface on the cell wafer. The nanoscale pores-on the order of a billionth of a meter in diameter-are much smaller than the wavelength of the incident light, so they suppress reflection across the full spectrum of sunlight. As the tiny holes deepen, they make the metallic gray silicon appear increasingly dark until it becomes almost pure black, absorbing nearly all frequencies of sunlight. The surface becomes riddled with minute pores of varying depths with no sharp interfaces that would reflect light, creating a highly absorbent silicon wafer.

Using a closely-related process that employs less-expensive silver nanoparticles, NREL has made a black silicon cell with a validated $18.2 \%$ conversion efficiencyabout the same efficiency as a typical crystalline silicon solar cell with a more costly antireflective coating.

At $100^{\circ} \mathrm{F}$, NREL's black silicon etching process takes less than a minute. In contrast, the etching process that prepares silicon wafers for conventional antireflective coatings takes 8-30 minutes, and applying the coatings adds even more processing time.

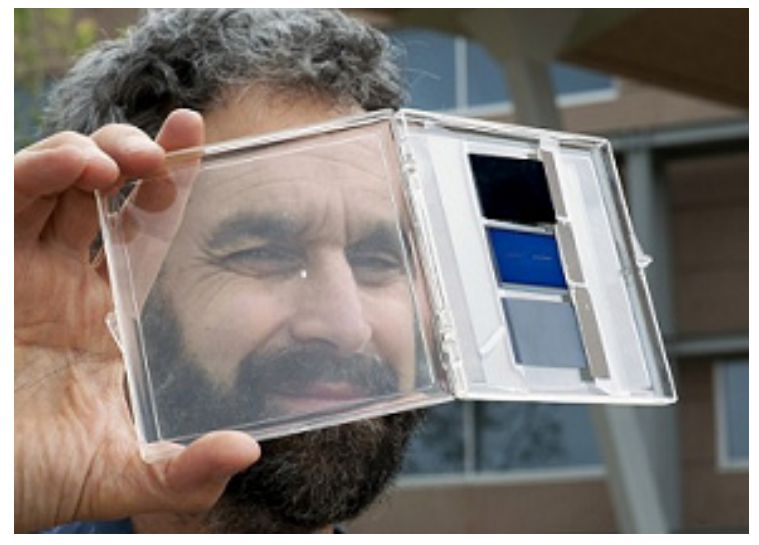

NREL Research Fellow Howard Branz examines silicon wafers with various antireflective treatments. The cells use the NREL black silicon method (top), a conventional antireflective coating with texturing (center), and the conventional texturing method only (bottom). Photo by Dennis Schroeder, NREL 17744 